\title{
NUEVOS BESTIARIOS EN LA LITERATURA ESPAÑOLA CONTEMPORÁNEA
}

\author{
FRANCISCO GONZÁLEZ GARCÍA \\ Université de Strasbourg
}

\begin{abstract}
RESUMEN
El artículo pretende mostrar cómo el bestiario, una de las formas literarias más antiguas que existen, se mantiene vigente en la literatura española de los siglos Xx y xxI. A partir de varios bestiarios de escritores contemporáneos (Javier Tomeo, Gustavo Martín Garzo, Daniel Nesquens, Ángel García López, etc.), proponemos una taxonomía que ayude a clarificar su utilidad actual. Revisamos, asimismo, las características del género, constatando no solo su vigencia, sino también su actualización y revitalización. PALABRAS CLAVE: bestiario, animales, monstruos, literatura española, contemporánea
\end{abstract}

\begin{abstract}
The article shows how the bestiary, one of the oldest literary forms, are still valid in the Spanish literature of the $x x$ and XxI centuries. From several bestiary of contemporary writers (Javier Tomeo, Gustavo Martín Garzo, Daniel Nesquens, Angel García López, José María Merino, José Luis Sampedro, Juan Jacinto Muñoz Rengel, etc.), we propose a taxonomy to help clarify the current use of the Spanish bestiary. In addition, we review the definition and characteristics of the genre.

KEY WORDS: bestiary, animals, monsters, Spanish literature, contemporary
\end{abstract}

A pesar de ser una de las formas literarias más antiguas que existen, el bestiario se mantiene vigente y con fuerza en la literatura contemporánea. Para el filósofo francés Jean Lacroix, «aujourd'hui on écrit encore, on écrit toujours et un peu partout des bestiaires» ${ }^{1}$ e incluso hemos asistido, como apunta Francisca Noguerol Jiménez, a una significativa «revitalización» ${ }^{2}$ del género en el último medio siglo de la narrativa hispana. Si bien es cierto que los bestiarios latinoamericanos de las últimas décadas (Borges, Arreola, Monterroso, Cortázar, etc.) se han convertido en el centro de atención de numerosos estudios, distinta suerte han corrido, sin embargo, los bestiarios españoles. Nos proponemos, por tanto, revisar la definición y las características del

\footnotetext{
Recibido: 03-03-2016 / Aceptado: 18-09-2016

${ }^{1}$ Lacroix, J., «Sur quelques bestiaires modernes», en Epopée animale, Fable, Fabliau, Gabriel Bianciotto y Michel Salvat (eds.), Actes du IV Colloque de la Socété Internationale Renardienne, París, Presses Universitaires de France, 1984, p. 255.

2 Noguerol JimÉnez, F., «Borges y Arreola: bestiario, biblioteca y vida», en Variaciones Borges, 33, 2012, p. 127.
} 
género, y ofrecemos, a partir de una selección de bestiarios españoles, una taxonomía para ayudar a clarificar su utilidad actual.

El término «bestiario» aparece en el Diccionario de la lengua española dela Academia por primera vez en 1947, definido como «En la literatura medieval, colección de fábulas referentes a animales reales o quiméricos». ${ }^{3}$ La definición, que se mantiene intacta hasta la 21 a edición (de 1992), no nos parece adecuada por dos razones principales. En primer lugar, porque, como pretendemos demostrar, el bestiario no está limitado al periodo medieval; hoy se siguen escribiendo bestiarios, que pueden, además, seguir o no las pautas de los bestiarios medievales. Y en segundo lugar, porque el bestiario no es una colección de fábulas. De hecho, ni siquiera tiene por qué ser moralizante. Como objeta Ignacio Malaxecheverría a la definición propuesta por Nilda Guglielmi, ${ }^{4}$ " "moralizante" solo define a determinados bestiarios - no, por ejemplo, el denominado bestiario "de Cambrai", cuyos animales no van seguidos de moralización alguna, ni el bestiario amoroso de Richard de Fournival $-»{ }^{5}$

En la 22. ${ }^{a}$ edición de su diccionario (de 2001), la Academia decide cambiar la definición de bestiario por la siguiente: ${ }^{6}$ «En la literatura medieval, colección de relatos, descripciones e imágenes de animales reales o fantásticos». ${ }^{7}$ Como puede observarse, la alusión a la fábula ha desaparecido, pero la definición sigue resultando inapropiada, no solo porque continúa considerando el bestiario como una forma exclusiva de la Edad Media, sino también por la conjunción copulativa «e» en «colección de relatos, descripciones e imágenes», ya que olvida que podemos encontrar bestiarios compuestos únicamente por textos o descripciones (sin imágenes), y viceversa, bestiarios en los que solo hay imágenes (sin ningún tipo de acompañamiento textual). Asimismo, si queremos acercarnos a su acepción más original, más medieval, la definición propuesta por la Academia restringe el bestiario a una colección de animales, excluyendo así las descripciones de otros motivos de la naturaleza que, como las plantas y los minerales, son frecuentes en los catálogos de los bestiarios del medievo. ${ }^{8}$

\footnotetext{
3 Real Academia Española, Diccionario de la lengua española, Madrid, Espasa-Calpe, 1947, s. v. Bestiario.

4 El bestiario «es una obra seudocientífica moralizante sobre animales, existentes y fabulosos». Guglielmi, N., y Ayerra Redín, M., El Fisiólogo. Bestiario Medieval, Buenos Aires, Editorial Universitaria de Buenos Aires / Eudeba, 1971, p. 7.

${ }_{5}$ MalaxecheVerría, I., Bestiario Medieval, Madrid, Ediciones Siruela, 2002, p. 22.

6 En la edición actual, la 23a , se mantiene la misma definición.

7 Real Academia Española, Diccionario de la lengua española, Madrid, Espasa-Calpe, 2001, s. v. Bestiario.

8 «En su acepción primigenia, un bestiario es un conjunto de comentarios -pretendidamente basados en la observación y el análisis científico- acerca de la naturaleza física y de los hábitos y comportamiento de diversas especies animales». Pedrosa Bartolomé, J. M., Bestiario. Antropología y simbolismo animal, Madrid, Medusa Ediciones, 2002, p. 217.
} 
Más idónea nos parece, por ejemplo, la definición que ofrece Eduardo Mendieta, para quien el bestiario es «un libro de bestias, una clase de enciclopedia o un compendio de las descripciones, $\mathrm{y}$, en muchos casos, representaciones gráficas de animales fantásticos e inusuales, aunque otras veces de animales más bien comunes y pedestres». ${ }^{9} \mathrm{Al}$ considerar el bestiario como un compendio de bestias, no solo los animales tienen cabida en estas recopilaciones, sino también el monstruo (fundamental en los bestiarios de todas las épocas), el cual puede ser un ser humano, un animal, un motivo natural, un híbrido, etc.

También muy acertada consideramos la definición ofrecida por Noguerol Jiménez, quien tampoco habla de los animales como protagonistas de los bestiarios, sino de «criaturas» reales o fantásticas. ${ }^{10}$

Una vez revisada brevemente su definición, y antes de adentrarnos en el análisis, ofrecemos al lector una clasificación de los bestiarios españoles contemporáneos en tres grandes categorías: 1) el bestiario que refleja la condición o las conductas humanas o el bestiario moral; 2) el bestiario que pretende mostrar lo poético, lo maravilloso o lo extraordinario; 3) el bestiario cómico. En cualquier caso, conviene resaltar que, aunque proponemos distintos tipos de bestiarios, estos son en realidad, como señala Esperanza López Parada, respuestas a un mismo problema: «el de la representación de una parte del mundo». ${ }^{11}$

Por otro lado, nos parece pertinente aclarar que habíamos pensado añadir otra categoría a la clasificación propuesta, la del bestiario enciclopédico, es decir, aquel que cuenta con una sustancia puramente descriptiva. Sin embargo, no hemos encontrado ningún bestiario actual que responda únicamente a estas indicaciones. Sí encontramos, en cambio, y con bastante frecuencia, bestiarios que mezclan la sustancia descriptiva con otra utilidad. Por ello, hemos decidido quitarlo de la clasificación, pero mantenerlo presente en nuestro análisis.

El primer tipo de bestiario propuesto es, por tanto, el bestiario que refleja la condición o las conductas humanas o el bestiario moral. Este bestiario es el que más se asimila a la fábula, pues suele utilizar a sus criaturas para reflejar (o criticar) el comportamiento humano. Y es también el más próximo a muchos bestiarios medievales, los cuales suelen contener un mensaje moral que debe descodificar el lector:

Los bestiarios fueron eminentemente trabajos religiosos y espirituales [...]. El bestiario cumplía una función pedagógico-espiritual. Fueron usados para educar

\footnotetext{
9 Mendieta, E., «El bestiario de Heidegger: el animal sin lenguaje ni historia», en Filosofía UIS, Vol. 11, 1, 2012, p. 20.

10 Noguerol JimÉNeZ, F., «Borges y Arreola [...]», art. cit., p. 128.

11 López Parada, E., Bestiarios americanos, Madrid, Universidad Complutense de Madrid. Servicio de Publicaciones, 2000, p. 26.
} 
a los cristianos sobre la beneficencia y la beatitud de la creación de Dios, su diseño moral y la forma cómo ese diseño se manifestaba en todas las cosas vivientes. ${ }^{12}$

Dentro de este primer tipo de bestiario, se encuentran, por ejemplo, muchas de las criaturas de los bestiarios de Javier Tomeo. El autor suele mezclar la descripción de la bestia (normalmente un animal) con una reflexión sobre ella o sobre el hombre. En la mayoría de los casos, encontramos una abundante sustancia descriptiva al principio del relato, $\mathrm{y}$, tras el primer o segundo párrafo, el animal discrepa sobre algo (algún cliché sobre él mismo, quizá) o cuenta alguna anécdota, convirtiéndose por tanto en algo más que en una simple descripción e invitando a la reflexión de los lectores. Veamos, por ejemplo, lo que el búho nos cuenta en uno de los bestiarios de Tomeo:

Soy ave de pico curvo y robusto, unos afilados y grandes ojos, que vive en las tinieblas y en la soledad. Vuelo durante las noches en busca de mis víctimas y la luna se convierte entonces en mi gran ahijada. La luz del sol me deslumbra y sólo abandono la madriguera cuando llega el crepúsculo.

Todavía no tengo muy claro, sin embargo, a qué fuerzas represento. Dicho de otro modo, no conozco aún mi propia identidad. Algunos dicen que soy ave de mal agüero y que mis chillidos anuncian la muerte. En otros tiempos, sin embargo, hubo poetas que me entronizaron como rey de todas las aves nocturnas y me consagraron a Juno, esposa de Júpiter. No faltaron incluso quienes me vieron a los pies de Minerva, la diosa de la ardiente mirada, protectora de los artistas.

Vivo pues en la duda. [...]

Algunas veces pienso si no seré únicamente una víctima de las propias dudas de los hombres. Puede, en efecto, que los hombres proyecten sobre mí las mismas incertidumbres que a ellos les roban el sueño y que haciéndolo así encuentren cierto alivio a sus angustias. ${ }^{13}$

Javier Tomeo comienza con la descripción del animal y, tras la inserción de la locución adversativa, introduce el componente más interesante: el ave duda de su identidad, convirtiéndose así en un reflejo de las propias incertidumbres del hombre.

Otro bestiario que podemos incluir en esta primera categoría es El libro de los pequeños milagros, de Juan Jacinto Muñoz Rengel, en el que el autor retrata metáforas críticas del ser humano. Valga como ejemplo el texto «Ganado», en el que tres vacas, que se han convertido en auténticos genios con capacidades extraordinarias, son sacrificadas por el Gobernador por el único motivo de haber dejado de dar leche. ${ }^{14} \mathrm{El}$ texto se convierte así en una crítica al sistema actual, el cual desprecia a muchos seres

\footnotetext{
12 Mendieta, «El bestiario de Heidegger...», art. cit., p. 20.

13 Tomeo Estallo, J., Cuentos completos, Madrid, Páginas de Espuma, 2012, p. 101.

14 Muñoz Rengel, J. J., El libro de los pequeños milagros, Madrid, Páginas de Espuma, 2012, p. 82.
} 
por el mero hecho de que no ofrecen lo que se espera de ellos (a pesar de que lo que puedan aportar al sistema sea mucho mejor de lo que se les pide).

También incluimos en este primer grupo el Bestiario de Ángel García López. A través de la animalización de los aspectos más negativos del ser humano, el autor hace una crítica bastante irónica de los vicios de la sociedad partiendo de la realidad cotidiana, sobre todo del mundo del trabajo y la oficina:

Parte de escenas concretas, de individuos y comportamientos conocidos, [...], pero el reto conseguido por su libro consiste en trascender las anécdotas, en saltar de los viciosos al vicio, hasta obtener una pintura abierta de los valores negativos del alma humana. ${ }^{15}$

El escritor ama y odia a todos sus animales, pues confiesa que, aunque puede distanciarse de ellos, no puede evitar verse reflejado: «En vosotros, a imagen, me defino»; «Gemelos de mi sombra»; y «edificados de mi mismo barro». ${ }^{16}$ A lo largo de su galería de criaturas, encontramos, entre muchos otros, a los siguientes animales, de los que ofrecemos su significado: el camaleón, que se esconde de las fieras mientras ve cómo matan a los otros reptiles y se queda solo, refleja la cobardía y la soledad humanas; el pingüino, con su traje de lacayo y «su mirada imbécil», representa a los ejecutivos que miran por encima del hombro al resto de los trabajadores; la foca madura, que tiene miedo de que la foca joven le robe los aplausos, refleja los celos y la competencia existente en el mundo del trabajo; y el buitre negro, que disfruta despidiendo a los cadáveres, es un reflejo del jefe de personal.

Por otra parte, el bestiario de García López refleja con bastante exactitud las ideas presentadas por John Berger en su ensayo «¿Por qué miramos a los animales?». ${ }^{17}$ Para este crítico, el animal tal y como lo conocíamos ha ido desapareciendo de la vida del hombre durante los dos últimos siglos. Así, aunque es cierto que las familias actuales siguen teniendo animales, ya no lo hacen por su utilidad habitual:

En el pasado, las familias de todas las clases sociales tenían animales domésticos porque eran útiles: perros guardianes, perros de caza, gatos ratoneros y otros. La costumbre de tener animales al margen de su utilidad es una innovación moderna y única en la historia, si tenemos en cuenta la escala social que hoy ha alcanzado este fenómeno. Forma parte de esa reclusión universal, aunque individualizada, en la intimidad de la pequeña unidad Familiar, decorada o amueblada con recuerdos del mundo exterior, que es una de las características propias de las sociedades de consumo. ${ }^{18}$

15 García Montero, L., «Prólogo», en Bestiario. Animalias, Ángel García López (ed.), Madrid, Eneida, 2000, pp. 9-20.

16 García López, Bestiario. Animalias, ob. cit., p. 21.

17 Berger, J., «¿Por qué miramos a los animales?», en Mirar, Barcelona, Gustavo Gili, 2001, pp. 9-31.

18 BERGER, J., «¿Por qué miramos a los animales?», ob. cit., p. 19. 
Asimismo, estos animales están «desnaturalizados», pues normalmente son esterilizados, aislados sexualmente, privados del contacto de otros animales y alimentados de forma artificial. Ni siquiera en el zoo, señala Berger, es posible recuperar la antigua relación hombre-animal. Aunque los visitantes suelen ir al parque zoológico a mirar a los animales, su mirada jamás se encontrará con la de ningún animal. ${ }^{19}$ Esto se debe a la total marginalización de este último: habita en un espacio artificial, suele tener luces artificiales, no tiene nada sobre lo que actuar (salvo el alimento que no tiene que buscar y la pareja que le es proporcionada) y está aislado; «De ahí que se apropien de una actitud por lo demás exclusivamente humana: la indiferencia». ${ }^{20}$

Al haber desaparecido este antiguo vínculo entre hombre y animales, estos últimos, piensa Berger, ya no pueden explicar el carácter de las personas ni pueden desenmascarar nada, aunque esto no significa que no pueda extraerse de ellos una moral. En el bestiario de Ángel García López, los animales, aunque conservan su forma exterior, han sido vaciados de su contenido animal. Por ejemplo, la foca ya no es ningún pinnípedo, sino que siente celos y desea el reconocimiento de los otros como los hombres; o el buitre negro, que es mucho más rapaz como jefe de personal que como ave.

Son, además, animales que se pasean por lugares que no le pertenecen, es decir, por espacios que únicamente forman parte del mundo humano, como es el caso de las oficinas de trabajo.

Aunque no se ciñen al mundo laboral, también hacen una crítica del comportamiento humano algunas bestias de otros autores, como el Antromóvil de José Luis Sampedro, un «diabólico engendro concebido para nuestra perdición y perteneciente al antimundo». ${ }^{21}$ La crítica no solo va dirigida a la criatura, sino también al ser humano, pues la satánica bestia (atractiva, inmóvil, con caparazón, ojos centelleantes y a la que por supuesto es necesario alimentar constantemente) despierta numerosos pecados en el hombre, como la soberbia, la avaricia y la envidia más amarga.

Para terminar con este primer grupo, mención especial merecen los hombres monstruosos de Javier Tomeo, los cuales se proponen perfeccionar nuestra forma de amar. ${ }^{22}$ Los monstruos de estos bestiarios no pretenden reflejar ningún aspecto de la

\footnotetext{
19 BERGER, J., «¿Por qué miramos a los animales?», ob. cit., p. 31.

20 BERGER, J., «¿Por qué miramos a los animales?», ob. cit., p. 29.

21 SAMPEDro SÁeZ, J. L., «Aviso contra la dañina bestia el Antromóvil donde se revelan sus disfrazadas artes y satánicos fines», en Gustavo Martín Garzo, et alii (eds.), Bestiario, Madrid, Siruela, 1997, pp. 163178.

22 Para un análisis más detallado sobre la monstruosidad en la obra de Javier Tomeo, cf. GonzáLEZ GARCíA, Francisco, «Amado monstruo de Javier Tomeo: un análisis del componente teratológico de la obra», en Analecta Malacitana, xxxvi, 1-2, 2013, pp. 161-195.
} 
conducta humana, pero sí se pueden considerar morales, pues el autor pretende que, a través de ellos, el lector sea capaz de amar lo monstruoso, lo que se aleja de lo normal y lo natural. Javier Tomeo utiliza principalmente al monstruo para que el hombre sea más indulgente con sus imperfecciones y para que aprenda a amarlo, es decir, sus seres monstruosos son una vía de perfeccionamiento interior para que el ser humano pueda llegar a amar sin límites.

Así, el monstruo «Amadeo», uno de los protagonistas de «Bestiario de invierno», es un hombre que tiene tres piernas y los ojos de distinto color, pero a pesar de ello tiene «los gustos y la sensibilidad $»^{23}$ de cualquier humano. Se trata de un hombre que puede existir en la realidad y que seguramente sería discriminado por su carácter monstruoso, por apartarse de lo que se considera «normal». Este monstruo nos sirve, como el resto de los hombres monstruosos del autor, para que todos nos reconozcamos en sus imperfecciones y seamos más indulgentes, llegando incluso a poder amarlo (o a poder amarnos).

También podríamos incluir en este tipo de monstruos al Cocatrix de Joan Fontcuberta. Este animal, catalogado de monstre historique, es un híbrido entre un cerdo y un anfibio. Todos le tienen miedo precisamente por apartarse de la norma, por no ser natural y por ser desconocido. Sin embargo, como señala acertadamente su ficticio investigador: «El temor a los cocatrix es sólo fruto de la ignorancia y de la superstición». ${ }^{24}$ $Y$ es que el monstruo no es solo lo diferente, sino que también participa de lo negativo al no ser conocido, ya que lo desconocido siempre supone una amenaza por el mero hecho de no conocerse: no sabemos de qué ser se trata ni tampoco qué porta consigo. Sin embargo, tenemos que aprender a ser capaces de amar lo que es diferente, lo que se aleja de la norma, pues solo así podremos amar de forma más perfecta.

El segundo tipo de bestiario que proponemos es aquel que se preocupa principalmente por lo poético, lo maravilloso y lo extraordinario, compuesto, en su gran mayoría, por seres fantásticos. A este tipo pertenecería, por ejemplo, el Bestiario de Rafael Pérez Estrada. El autor nos muestra, de una forma mucho más lírica que los autores anteriores, un amplio catálogo de seres maravillosos que no existen en nuestro planeta, convirtiendo la realidad en un mundo exquisito:

El acierto del poeta no está en decir lo que los demás dicen, sino con esos materiales de acarreo crear criaturas nuevas; digamos inventar mundos con palabras corrientes, y los mundos descubiertos hacen que las palabras se nos presenten como recién acuñadas. De lo consabido surge lo inédito. ${ }^{25}$

\footnotetext{
23 Tomeo Estallo, J., «Amadeo», art. cit., p. 33.

24 FOnTCUbertA, J., «El cocatrix», ob. cit., p. 45.

25 Alvar López, M., «La transmutación de los bestiarios», en Nuevos estudios y ensayos de la literatura
} 
Incluyendo un abundante componente descriptivo, encontramos en su Bestiario numerosas criaturas extraordinarias como: el elefante ónix, que destruye todo lo que ama; el ibi amatista, que no puede dejar de volar porque no tiene donde posar sus patas; o el pinzón de la noche, que se alimenta de los rayos de luna, provocando la oscuridad en donde vive. Aparecen, además, en este compendio, numerosos animales relacionados con los amantes y el amor: el sangre de pichón, un pájaro que se asimila a una llama y que nace de la pasión de los amantes; o la falsa estrella, un pequeño ser que guía a los enamorados hasta lo que desean conseguir.

Aunque la mayoría de los seres de este bestiario pretenden ser el reflejo de un mundo nuevo, singular y extraordinario, también encontramos algunas criaturas que podrían clasificarse en el apartado anterior, por suponer una crítica al comportamiento humano. Valga como ejemplo el $k u$, un diminuto pájaro, híbrido de mosca y colibrí, que se alimenta de las lagrimas de aquellos que lloran por los excesos del hombre cometidos contra la naturaleza.

Otro ejemplo de criaturas que estarían incluidas en este segundo tipo de bestiario son el Gamusino doméstico, de Jose María Merino y Block, de Gustavo Martín Garzo. El primer animal, un ser cuya característica fundamental es su invisibilidad («única evidencia que nadie, hasta ahora, ha conseguido refutar» ${ }^{26}$ ), actúa como metáfora de las sensaciones. Al ser invisible, las pruebas de que existe no son muy abundantes y son meras señales físicas: su respiración nos provoca el aire que a veces sentimos en la nuca o en las orejas; sus huellas son las deformaciones que vemos en las colchas o los cojines; y su canto se confunde con el goteo del grifo, la descarga de la cisterna o el tictac del reloj.

La segunda criatura, Block, es «un animal inclasificable, alejado de todas las especies conocidas». ${ }^{27}$ Lo poco que sabemos de él es que se esconde durante largos periodos de tiempo, que es aficionado al azúcar y el chocolate, que teme a los animales aéreos, que se muestra más activo por la noche, y que le gusta moverse entre cajas. En cuanto a su físico, tan solo se nos dice que tiene patas, hocico y ojos. El animal aparece vinculado a la figura de la mujer, pues es una mujer, Ángela, la dueña de esta criatura. Pensamos que la criatura puede ser una metáfora de la felicidad, ya que en todas las ocasiones en las que aparece los protagonistas manifiestan su estado de máxima satisfacción. Si el animal se esconde, el protagonista espera a que vuelva y lo busque: «No siempre lo hace, pero cuando esto sucede mi dicha no conoce límites». ${ }^{28}$

contemporánea, Madrid, Consejo Superior de Investigaciones Científicas, 1991, pp. 153-160.

26 Merino, J. M., «Gamusino doméstico», art. cit., p. 32.

27 Martín Garzo, G., «Mi vida con Block», ob. cit., p. 62.

28 Martín Garzo, G., «Mi vida con Block», ob. cit., p. 72. 
Cuando el protagonista lo mete en el coche y lo escucha moverse, recuerda «lo feliz que había sido con Ángela». ${ }^{29} \mathrm{Y}$ al final del relato, después de que Block se pierda y finalmente regrese, el protagonista nos confiesa lo siguiente: «Mi alegría tiene una causa, he encontrado a Block». ${ }^{30}$

En último lugar, el tercer tipo de bestiario que hemos propuesto es el bestiario cómico. Es preciso aclarar que en él no se encuentran los bestiarios que tienen tintes cómicos o irónicos, sino solo aquellos que hacen de la comicidad su principal objetivo. Los principales bestiarios españoles que se encuentran en esta última categoría son los bestiarios infantiles o juveniles, que buscan parodiar el género para sacar la risa de los lectores más jóvenes. Un buen ejemplo de ellos es el bestiario Hasta (casi) 100 bichos de Daniel Nesquens, en el que encontramos un amplio catálogo de animales (la mayoría reales) ordenados alfabéticamente. Para romper con el modelo y provocar la comicidad, Nesquens se sirve de cinco elementos principales.

El primero, y fundamental, es el juego de palabras con el nombre de los propios animales, utilizando principalmente la homonimia: así, la alpaca se parece a la llama, pero no quema; la araña no araña; el buitre no se gasta el dinero en comida fresca (ni con los amigos); al flamenco no le gusta el flamenco; el ganso tiene que hacer el ganso para no ser confundido con el pato; y el león, que huele a tigre, no es de León, sino de Salamanca.

El segundo elemento de comicidad consiste en mezclar la descripción científica del animal con una descripción normalmente muy informal. De este modo, el mapache «es mamífero, es euterio, es carnívoro, es cánido y es muy aficionado a dibujar con un palito en la tierra»; ${ }^{31}$ y el rodaballo «es un pez teleósteo anacanto, de carne muy estimada por los restauradores y comensales». ${ }^{32}$

En tercer lugar, Daniel Nesquens inventa el porqué de algunas características de sus animales, otorgándoles rasgos humanos y contemporáneos que no le son propios. Así, la araña crea su hilo para poder «andar, correr, jugar un partido de fútbol, o bailar un tango»; $; 3$ el camello «tiene dos jorobas, que ganó una tarde jugando una partida de póquer en un oasis del desierto del Gobi»; ${ }^{34}$ o la nutria «puede permanecer ocho minutos bajo el mar y catorce minutos esperando su turno en la panadería». ${ }^{35}$

\footnotetext{
29 Martín Garzo, G., «Mi vida con Block», ob. cit., p. 76.

30 Martín Garzo, G., «Mi vida con Block», ob. cit., p. 80.

31 Nesquens, D., Hasta (casi) 100 bichos, Madrid, Anaya, 2001, p. 117.

32 Nesquens, D., Hasta (casi) 100 bichos, ob. cit., p. 161.

33 Nesquens, D., Hasta (casi) 100 bichos, ob. cit., p. 19.

34 Nesquens, D., Hasta (casi) 100 bichos, ob. cit., p. 37.

35 Nesquens, D., Hasta (casi) 100 bichos, ob. cit., p. 127.
} 
En cuarto lugar, el autor utiliza varias descripciones que en ocasiones rozan el absurdo por su evidencia. Por ejemplo, el águila «es un ave rapaz del tamaño de un águila, color de águila, cola de águila [...]»; ${ }^{36}$ y la cigüeña más común «es la blanca. La negra es más peculiar. La blanca es más clara, y la negra más oscura». ${ }^{37}$

En último lugar, se utilizan constantemente ingeniosas asociaciones de ideas. De esta forma, «El mayor pasatiempo de la avispa es pinchar los globos que los niños llevan de un cordel cuando pasean por la feria, entre norias y tiovivos»; 38 "La casa del caracol es una concha en forma de espiral. Menos en Egipto, que es en forma de pirámide»; ${ }^{39}$ "El seis de enero el dromedario se queda en casa, junto al teléfono, por si por casualidad hay alguna baja [de camellos] de última hora»; ${ }^{40}$ y el yak «se llama yak porque tenía que haber algún animal que empezase por la letra $\mathrm{Y}_{{ }_{»} .}{ }^{41}$

Como puede observarse, Daniel Nesquens conserva la forma del bestiario y el componente descriptivo de sus animales, aunque se vale de las técnicas vistas para rehacerlo y ofrecer una utilidad diferente.

En conclusión, podemos afirmar que se siguen escribiendo bestiarios en la actualidad, aunque traicionan, en mayor o menor medida, el modelo tradicional para ofrecérsenos desde nuevas perspectivas. En la literatura española contemporánea podemos encontrar, como hemos visto, diferentes tipos de bestiarios según la mirada de su escritor y su objetivo a la hora de escribir: bestiarios morales o que reflejan los comportamientos humanos; bestiarios que pretende mostrar lo poético, lo maravilloso o lo extraordinario; y bestiarios que hacen de la comicidad su principal objetivo. En cualquier caso, lo importante es que el género se mantenga vivo y que los animales y las bestias nos continúen sirviendo para reflexionar sobre nuestras inquietudes y nuestro mundo.

\section{Bibliografía}

Alvar López, Manuel, «La transmutación de los bestiarios», en Nuevos estudios y ensayos de la literatura contemporánea, Madrid, Consejo Superior de Investigaciones Científicas, 1991, pp. 153-160.

Berger, John, «¿Por qué miramos a los animales?», en Mirar, Barcelona, Gustavo Gili, 2001, pp. 9-31.

\footnotetext{
36 Nesquens, D., Hasta (casi) 100 bichos, ob. cit., p. 15.

37 Neseuens, D., Hasta (casi) 100 bichos, ob. cit., p. 45.

38 Nesquens, D., Hasta (casi) 100 bichos, ob. cit., p. 14.

39 Nesquens, D., Hasta (casi) 100 bichos, ob. cit., p. 39.

40 Nesquens, D., Hasta (casi) 100 bichos, ob. cit., p. 54.

41 Nesquens, D., Hasta (casi) 100 bichos, ob. cit., p. 202. 
Fontcuberta, Joan, «El cocatrix», en Bestiario, Gustavo Martín Garzo, et alii (eds.), Madrid, Siruela, 1997, pp. 11-52.

García López, Ángel, Bestiario. Animalias, Madrid, Eneida, 2000.

García Montero, Luis, «Prólogo», en Bestiario. Animalias, Ángel García López (ed.), Madrid, Eneida, 2000, pp. 9-20.

GonzÁlez GarcíA, Francisco, «Amado monstruo de Javier Tomeo: un análisis del componente teratológico de la obra», en Analecta Malacitana, xxxVI, 1-2, 2013, pp. 161-195.

Guglielmi, Nilda, y Ayerra Redín, Marino, El Fisiólogo. Bestiario Medieval, Buenos Aires, Editorial Universitaria de Buenos Aires / Eudeba, 1971.

GutiérRez, Menchu, et alii, «Bestiario de invierno», en El Urogallo, 115, 1995, pp. 26-37.

LACroIX, Jean, «Sur quelques bestiaires modernes», en Epopée animale, Fable, Fabliau, Gabriel Bianciotto y Michel Salvat (eds.), Actes du IV Colloque de la Socété Internationale Renardienne, París, Presses Universitaires de France, 1984, pp. 255-268.

López PARAdA, Esperanza, Bestiarios americanos, Madrid, Universidad Complutense de Madrid. Servicio de Publicaciones, 2000.

MalaXecheVerría, Ignacio, Bestiario Medieval, Madrid, Ediciones Siruela, 2002.

Martín Garzo, Gustavo, et alii, Bestiario, Madrid, Siruela, 1997. , «Mi vida con Block», en Martín GARzo, Gustavo, et alii, Bestiario, Madrid, Siruela, 1997, pp. 53-84.

MENDIETA, Eduardo, «El bestiario de Heidegger: el animal sin lenguaje ni historia», en Filosofía UIS, Vol. 11, 1, 2012, pp. 17-43.

Merino, José María, «Gamusino doméstico», en Menchu Gutiérrez, et alii (eds.), «Bestiario de invierno», El Urogallo, 115, 1995, pp. 31-32.

Muñoz Rengel, Juan Jacinto, El libro de los pequeños milagros, Madrid, Páginas de Espuma, 2012.

NesQuens, Daniel, Hasta (casi) 100 bichos, Madrid, Anaya, 2001.

Noguerol JimÉnez, Francisca, «Borges y Arreola: bestiario, biblioteca y vida», en Variaciones Borges, 33, 2012, pp. 127-148.

Pedrosa Bartolomé, José Manuel, Bestiario. Antropología y simbolismo animal, Madrid, Medusa Ediciones, 2002.

Real Academia Española, Diccionario de la lengua española, Madrid, Espasa-Calpe, 1947. , Diccionario de la lengua española, Madrid, Espasa-Calpe, 2001.

SAmpedro SÁez, José Luis, «Aviso contra la dañina bestia el Antromóvil donde se revelan sus disfrazadas artes y satánicos fines», en Gustavo Martín Garzo, et alii (eds.), Bestiario, Madrid, Siruela, 1997, pp. 163-178.

Tomeo Estallo, Javier, Cuentos completos, Madrid, Páginas de Espuma, 2012. , «Amadeo», en Menchu Gutiérrez, et alii (eds.), «Bestiario de invierno», El Urogallo, 115, 1995, pp. 36-37. 